\title{
Transformation of corporate governance in the context of digitalization of the economy
}

\author{
Tatiana Kuzminova*, Ilya Marushcak, Natalia Onanko, and Alexander Yurasov \\ Moscow International University, Leningradsky Prospect, 17, 125040 Moscow, Russia
}

\begin{abstract}
The purpose of the work is to identify areas for improving the efficiency of corporate governance in the context of the digitalization of the economy. The characteristic features of a corporation as a system, the development of which is influenced by its subsystems and supersystem, have been highlighted and described. It has been shown that the quality of management impact on a corporation depends on how fully the experience of the corporation's development in the past is taken into account. Adequate forecasting of its possible states in the future is also important. Based on the study of the triad of the processes of development of socioeconomic systems (ontogenesis, phylogenesis and technogenesis), it is shown that currently there is an imbalance caused by a sharp acceleration of technogenesis. The dialectical consideration of the triad of developmental processes led to the conclusion that the imbalance was caused primarily by the exacerbation of the contradiction between technogenesis and ontogenesis. As a point of relevance for resolving the revealed contradiction, it is proposed to shift the emphasis in corporate management to phylogenesis. Specific measures for the development of phylogonese in corporations are the introduction and development of new forms of joint activities, the transformation of organizational structures, the creation of an atmosphere of mutual understanding, justice, morality, ethics, and culture.
\end{abstract}

\section{Introduction}

The quality of control is determined by the depth and adequacy of the control subject's ideas about the controlled object. The holistic perception of the control object implies knowledge of its past, present and forecasting the future both at the level of the control object itself (modeled as a system of interconnected elements) and at the level of its subsystems and supersystems (Fig. 1). In this case, as a general rule, the goals of the system development lie in the supersystem, and the most effective are the impacts on the system from the supersystem. In the absence of an opportunity to influence from the supersystem, one can go down to the level of the subsystems. The properties of the elements (subsystems) of the system are determined by their interaction with other elements, therefore, a change in the structure of these interactions leads to a change in the system

*Corresponding author: tvk-07@mail.ru 
itself. It is currently being actively used to implement change in corporations. A change in the organizational structure leads to changes in the characteristics of the corporation itself $[1,2]$.

At the corporate level, this manifests itself as three distinct models. There are AngloAmerican, Japanese and German models of corporations. While maintaining the common elements characteristic of any corporate governance system (shareholders, directors, managers), different rules of interaction between participants lead to differences in the properties of corporations. For example, if in Japanese corporations, interaction is aimed at establishing long-term business ties, then in American corporations - at establishing a balance of power.

\begin{tabular}{|c|c|c|c|}
\hline & Past & Present & Future \\
\hline Supersystem & $\begin{array}{c}\text { Subject of analysis for } \\
\text { the purpose of making } \\
\text { a management } \\
\text { decision }\end{array}$ & $\begin{array}{c}\text { Subject of analysis for } \\
\text { the purpose of making } \\
\text { a management } \\
\text { decision }\end{array}$ & $\begin{array}{c}\text { Management impacts } \\
\text { that lead to changes in } \\
\text { the state }\end{array}$ \\
\hline System & $\begin{array}{c}\text { Subject of analysis for } \\
\text { the purpose of making } \\
\text { a management } \\
\text { decision }\end{array}$ & $\begin{array}{l}\text { Real state of the } \\
\text { control object }\end{array}$ & $\begin{array}{l}\text { Desired state of the } \\
\text { control object }\end{array}$ \\
\hline Subsystems & $\begin{array}{c}\text { Subject of analysis for } \\
\text { the purpose of making } \\
\text { a management } \\
\text { decision }\end{array}$ & $\begin{array}{c}\text { Subject of analysis for } \\
\text { the purpose of making } \\
\text { a management } \\
\text { decision }\end{array}$ & $\begin{array}{c}\text { Organizational } \\
\text { changes that support } \\
\text { changing the } \\
\text { management object }\end{array}$ \\
\hline
\end{tabular}

Fig. 1. Management object as a complete system

Differences in the integral properties of corporations are also manifested in the transparency of their functioning, widely discussed by scientists and practitioners, which has both positive and negative effects on all participants in socio-economic relations [3]. The national composition of its members leaves its imprints on transnational corporations [4]. This reflects not only the interaction of elements in the system, but also the qualities of the elements that they manifest outside the system.

Possible options for the development of a controlled object under the influence of managerial influences depend on many factors located both in the internal environment of the control object (the level of the system and subsystems) and in the external (at the level of the supersystem) $[5,6]$. It should be remembered here that the interaction of factors with each other also leads to a synergistic effect that distinguishes the final impact from the sum of the impacts of all factors as independent ones. At the same time, the level of uncertainty also rises, requiring special competencies from the manager in making decisions [7].

A distinctive feature of the modern stage of development of society is the rapid development of digital technologies, which led to the acceleration of the course of all socioeconomic processes. "In 2017, the combined value of digital platforms with a market capitalization of more than $\$ 100$ million exceeded an estimated $\$ 7$ trillion, which is $67 \%$ more than in 2015" [8, P. 8]. "The dynamics of global Internet traffic in 2002 was $100 \mathrm{~GB}$ per second, in $2007-2000 \mathrm{~GB}$, in $2017-46000 \mathrm{~GB}$, by 2022 it is expected $150700 \mathrm{~GB}$ per second" [8, P. 2].

Management is increasingly faced with situations where previously well-functioning management methods lose their effectiveness in new conditions. The reason for this is the qualitative changes in interactions both within the corporation between the divisions and the corporation with external stakeholders as a result of a sharp increase in the amount of information that supports all socio-economic processes. 
In these conditions, a further increase in the efficiency of corporate management systems is possible only with an emphasis on the processes occurring in the supersystems, identifying and taking into account the objective laws of the functioning of society in general and the economy in particular.

\section{Methodological approaches and research methods}

From the point of view of dialectics (ideal for G. Hegel and materialistic for K. Marx) development is a consequence of the manifestation of objective laws. Corporations change according to system laws. From the point of view of making managerial decisions, the most important of them is the unity and struggle of the opposites. At the same time, the formation and resolution of contradictions of the corporation is ensured by objectively different development goals: the corporation and its divisions (systems and its subsystems), different divisions of the corporation (different subsystems of the unified system), the corporation and the socio-economic system of the regions where the corporation's products are sold (systems and supersystems).

Another important dialectical law from the point of view of the issues under consideration is the transition from quantity to quality. The rapid growth in the amount of information, provoked by the intellectual activity of people, has led to a qualitative change in all spheres of society. This is one of the key reasons for corporations are undergoing changes that reduce the effectiveness of management practices that have proven to be reliable in the industrial age.

The fractality of the development of all life on Earth will make it possible to draw an analogy between the two extreme forms of power in society (dictatorship and democracy) [9, p. 208] and the priority of the participants in the management of the corporation (the board of directors and shareholders). At each moment in time, the corporate governance system is represented by a certain ratio of the power of the board of directors and shareholders. "The crisis of power comes when it is appropriate only for a very limited number of people or is not able to limit the dangerous individual or group egoism of people" [9, p. 209]. People in the corporation and its external environment are all its members and stakeholders. If earlier management considered customer satisfaction to be the most important element of its activities, then the modern management paradigm asserts that success is impossible without harmonious coordination of the interests of all stakeholders, individual and group ones.

\section{Results and Discussion}

The resolution of any contradiction must use a point of relevance that differs from the poles that entered the dialectical struggle. For this, it is necessary to move from a pair of opposites to a triad, as it happens, for example, in biological systems. Today, many models of objects of leadership in management are built by analogy with how biological systems manifest themselves. In this case, biological terms are borrowed. For example, it is widely known that corporations are divided according to the type of innovative behavior into violets, patents, exporters and commutators. Continuing this tradition, the modern researcher of business systems A.G. Teslinov proposed to consider the development of all socio-economic systems from the point of view of the simultaneous occurrence of three processes: two, similar to processes in all biosystems (phylogenesis and ontogeny) and the third, created by the creativity of people, characteristic only for human society technogenesis [10]. With regard to a corporation developing in the context of digitalization, it looks like this (Figure 2). 
The contradictions that ensure development are exacerbated at each specific moment, mainly between two processes, the development of the third serves as a point of relevance for its resolution.

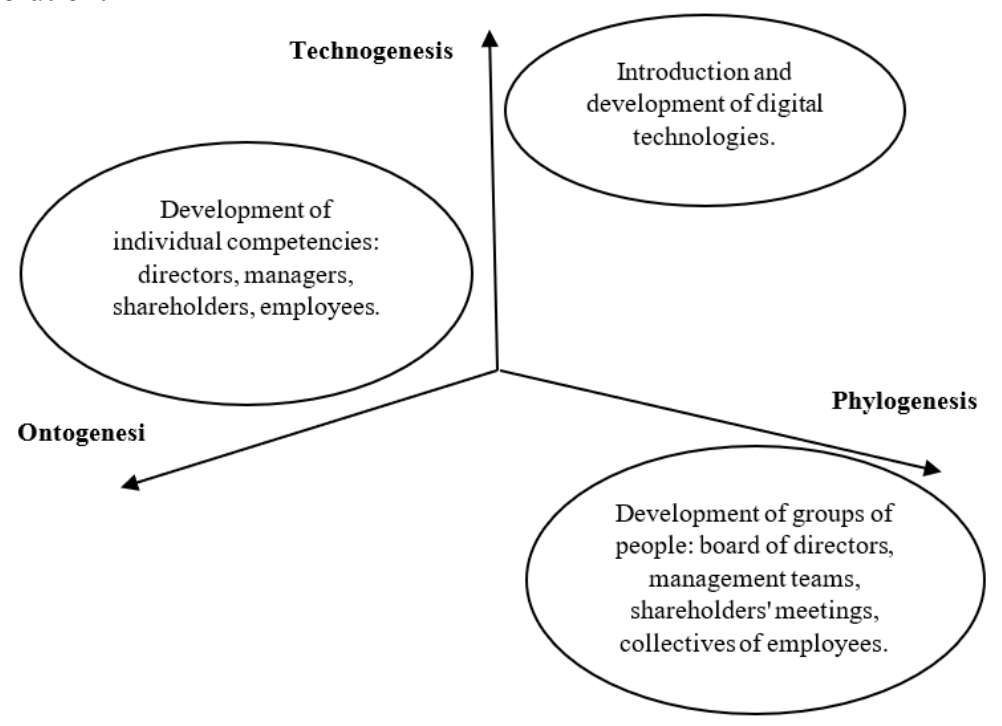

Fig. 2. The evolutionary whole of a corporation in the context of the digitalization of the economy

In our opinion, the contradiction between technogenesis, which is developing at an excessively fast pace, and ontogenesis, which is the basis of all democratic processes, has now sharpened, which has led to many ethical problems $[11,12]$, the resolution of which is possible by accelerating the development of phylogenesis. At the corporate level, "the development of phylogenesis is the emergence of new norms of joint activity, organizational structures, mutual understanding, justice, morality, ethics, culture" [10].

The triad of integrity is manifested at all levels of socio-economic systems. An attempt to look at the processes of globalization from the point of view of reducing costs [13] also reflects the manifestation of the development of the triad processes (Fig. 3).

The era of the Enlightenment and the New Age was preceded by the Renaissance, which returned human attention to the center, ontogenesis was accelerated, which led to geographical discoveries and many inventions that made it possible to reduce the cost of moving goods. This was the first stage of globalization.

"The second acceleration of globalization took place in the $1990 \mathrm{~s}$, when the ICT revolution drastically lowered the cost of moving ideas" [13]. Here the priority of the development of technogenesis is obvious, which is shown in Figure 3 and reflected by the central blocks.

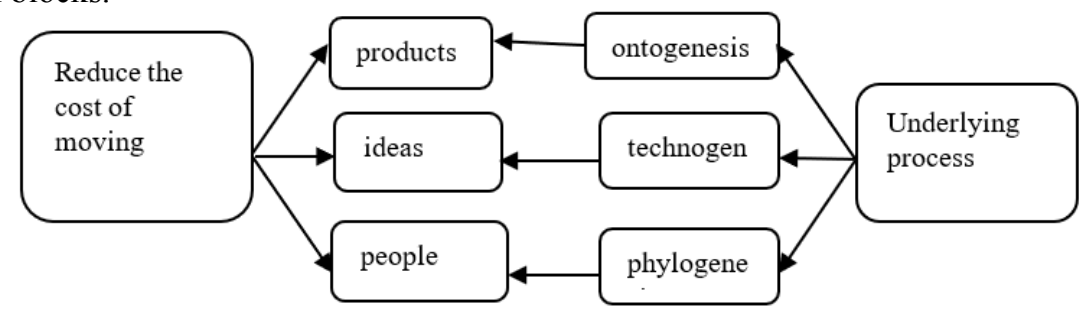

Fig. 3. Manifestation of the development triad in the cost of moving goods, ideas, and people 
Further, R. Baldwin [13] predicts a third reduction in expenses, costs of moving people, which corresponds to the activation of phylogenesis and is designated by us as the direction of transformation of the corporate management system. Currently, this process manifests itself in the form of corporate social responsibility aimed at harmonizing the interests of all stakeholders of the corporation - both internal and external. In the future, the emphasis on these processes will be a condition for the effective management of corporations in the context of digitalization of all spheres of society.

\section{Conclusions}

1. The corporation exhibits properties that are common to all systems. Until recently, the effectiveness of corporate management depended on the ability to take a holistic view of it as a system.

2. A corporation, like any living system, develops according to dialectical laws, the main of which (from the point of view of making managerial decisions) is the formation and resolution of contradictions.

3 . In any corporation, three processes occur simultaneously - phylogeny, ontogeny and technogenesis. For the long-term development of a corporation, a balanced development of all processes is necessary.

4. The digitalization of society has led to a significant bias of the development triad towards technogenesis, which has caused many ethical problems in society in general and at the level of corporations in particular.

5. Bringing the corporate development triad into balance requires a redistribution of management's attention to addressing phylogenetic issues, including the development of corporate ethics and culture.

\section{Acknowledgements}

The article has been prepared within the framework of the research project of ANOVO "Moscow International University" on the topic "Management in the digital economy: Russian and international experience."

\section{References}

1. S.P. Zemtsov, A.V. Chernov, Journal of the new economic association, 1(41) (2019)

2. S.V. Shibaev, I.I. Marushchak, Economic Systems, 11(1), 60 (2018)

3. T. Rovinskaya, Mirovaya ekonomika i mezhdunarodnye otnosheniya, 64 (2020)

4. T. V. Kuzminova, V. A. Prokudin, Consolidation of intellectual resources as a Foundation for the development of modern science: collection of articles of the International scientific and practical conference (2020)

5. David Henriques, Ruben Pereira, Rafael Almeida, Miguel Mira da Silv, FORESIGHT and sti governance, 14 (2020)

6. T. V. Divina, N.A. Onanko, A. B. Yurasov, FES: Finance, Economy, Strategy, 15 (2018).

7. E. Vashurina, T. Bazarov, Organizational psychology, 10 (2020)

8. Digital economy report 2019: creating value and generating benefits: implications for developing countries, Review, 16 (2019) 
9. V.G. Maslennikov, Theory of change, Experience of combining ancient and modern knowledge, 251 (2000)

10. A. G. Teslinov, The concept of development, The first stage of comprehension of development, (2019) http://edu.dbaconcept.ru/

11. T. V. Kuzminova, Scientific achievements of higher education 2020: collection of articles of the International research competition (2020)

12. Ethics and "digital issues": Ethical problems of digital technologies, 207 (2020)

13. R. Baldwin, Journal of Economic Sociology, 18 (2017) 